\title{
Functional Condition of Cattle with Demodicosis Disease
}

\author{
Stolbova O.A. \\ Candidate of Veterinary Sciences, Associate Professor \\ Federal State Budgetary Educational \\ Institution of Higher Education \\ «Northern Trans-Ural State Agricultural University», \\ Tyumen, Russia \\ All-Russian Research Institute of Veterinary \\ Entomology and Arachnology, SB RAS, \\ Tyumen, Russia \\ e-mail: stolbovaoa@gausz.ru
}

\author{
Skosyrskikh L.N. \\ Candidate of Veterinary Sciences, Associate Professor \\ Federal State Budgetary Educational \\ Institution of Higher Education \\ «Northern Trans-Ural State Agricultural University», \\ Tyumen, Russia \\ e-mail: skosyrskyshln@gausz.ru
}

\begin{abstract}
Cattle demodicosis takes a special place among parasitic diseases. It causes economic damage due to considerable reduction of meat and milk production, quality of rawhide, reduction of the breeding value of young stock, body resistivity and even the death of animals. The purpose of the study was to analyze the current status of cattle demodicosis and the functional condition of organism at this pathology in Northern Trans-Ural region. Cattle demodicosis is widespread in Tyumen region (prevalence: $43.5 \pm 1.03 \%$ ). The incidence rate of demodicosis in farms and complexes on the production of milk, beef and the rearing stock makes from 1.5 to $44.6 \%$. The smallest indicators of extensiveness and intensity of invasion were observed in bull-calves on feed $-\mathbf{4 . 9 \%}$ and in the young stock up to 12 months old $-11.2 \%$, while the highest indicators were observed in heifers of $\mathbf{1 . 5 - 2}$ years old $-\mathbf{5 6 . 7 \%}$ and cows $-\mathbf{1 9 . 8 \%}$. During the study the animals had the following prevalence levels: low $-\mathbf{7 3 . 6 \%}$, average $-\mathbf{2 2 . 5 \%}$, high $-3.1 \%$, generalized $-0.8 \%$. Morphological and biochemical blood tests showed that the demodectic invasion was accompanied by the decrease in quantity and volume of erythrocytes, hemoglobin content and concentration in erythrocytes, which indicates the decrease of oxygen delivery to tissues and organs of animals. The reduction of monocytes and lymphocytes indicates the immunosupressive action of Demodex bovis on the host organism and failure of immune T-system. The parasitizing with Demodex bovis damages liver, kidneys and metabolism of cattle organism in general.
\end{abstract}

Keywords - cattle, parasites, mites, demodicosis, blood, microscopy, Demodex

\section{INTRODUCTION}

There is an opinion that Tyumen region is a petroleum center, and all other industries are considered secondary, including agricultural production. It is valid to say that these days the region uses its best endeavors to develop the agricultural sector, and the production of milk and meat is the primary agricultural area. Over the last five years, the Tyumen region witness a breakthrough in the development of agroindustrial complex. Even in crisis conditions, through the support of regional authorities the agricultural business of the region did not reduce the production volumes in all main directions. Due to such patronage, Tyumen region was included into the four top regions on the development of agro- industrial complex. Naturally, the state policy aimed to support the agricultural sector led to the increase in cattle population, which increased 2.6 times only in the sector of meat cattle breeding from 2008 for 2012 [1, 4, 5, 8, 15].

Undoubtedly, the maintenance of genetic efficiency of animals and the increase of economic indicators of production is impossible without the prevention of damage caused by various diseases of farm animals. Thus, it is critically important to prevent parasitical diseases in order to ensure the livestock production efficiency.

The cattle diseases caused by ectoparasites are widespread in farms of Northern Trans-Ural region. This group of pathologies represents a serious threat to animals since cattle ectoparasites include inflammatory skin reactions, anxiety, and as a consequence, loss of meat and dairy production. One of the problems of cattle invasive pathology is demodicosis $[2$, $3,6,7,9]$.

Demodicosis is a disease caused by the microscopic mites Demodex bovis living in hair bulbs and follicles and skin sebaceous glands in separate colonies. The demodectic mites damage large areas of skin integument, and sometimes the entire skin, which is negative for the general health of animals, their immune status, as well as for the reduction of cattlehide value being the main type of raw materials in leather industry [2-5].

It is known that blood is one of the body fluids, which supplies organs, tissues and cells with the necessary substances (vitamins, macro- and microelements, etc.) and ensures the removal of metabolism products. The change of morphological and biochemical structure of blood indicates latent stages of a body disease caused by metabolic disorder [11].

It is known from the clinical practice that chronic dermatitis causes secondary systemic and organ pathology mainly influencing the liver and kidneys. Hence, the identification of morphological and biochemical disorders in a macroorganism provides for more clear understanding of metabolic changes, which is important not only in realizing 
the pathogenesis, but also in taking certain therapy measures [9-14].

The purpose of the study is to analyze the current status of cattle demodicosis and the functional condition of organism at this pathology in Northern Trans-Ural region.

\section{MATERIALS AND METHODS}

The study has been carried out during 2002-2018 jointly by the Department of Noncontagious Diseases of Farm Animals and Infectious and Invasive Diseases of Northern Trans-Ural State Agricultural University, the Laboratory of Acarology of the All-Russian Research Institute of Veterinary Entomology and Arachnology - affiliate of Tyumen Research Center of SB RAS, and farms of Tyumen region. The study covered the cattle of milk, meat and meat-dairy production of various age groups. The diseased animals were detected through physical examination and hair cover palpation, as well as through microscopic study of demodectic colonies. During physical examination the attention was paid to hair loss and hair whorls, during palpation - to induration, pachymenia, scab, etc. The diagnosis was confirmed with a microscopic study of samples taken from affected areas. The content of demodectic pachymenia was obtained through deep scraping with a scalpel, then the material was placed on a glass slide, filled with several drops of water, evenly distributed on a glass with slight movements of a scalpel or a needle and then studied under low-power microscope in a dark field of view. In cases when clinical features of demodicosis were not revealed, the examination included the pulling of the hair cover in the area of $1.5-2 \mathrm{~cm} 2$ in the most frequent localization of demodectic colonies (neck, brachium, scapula) and taking skin scrapings and roots of the pulled-out hair from these places to detect the demodectic mites. In other cases, having removed a scab, it was possible to squeeze out from a papule a small amount of pasty content mainly consisting of mature Demodex bovis. The seasonal dynamics of cattle demodicosis was studied by monthly clinical examination.

The whole blood served the material for morphological study, while the blood serum - for biochemical. In total 31 animals selected by analogy and forming 4 groups participated in the experiment: 3 test $(n=7)$ and one control $(n=10)$ groups. The first test group included animals with low prevalence of demodectic mites, the second - average and the third group high degree of prevalence. The black-motley cows aged from 1 to 5 years took part in the experiment. The blood was taken into the vacuum test tubes from the caudal vein in the morning before feeding. Biochemical indicators were defined via semiautomatic analyzers Medonic Sa 620 in the clinical diagnostic laboratory of Northern Trans-Ural State Agricultural University and Mindray BA 88A in the biochemical laboratory of the All-Russian Research Institute of Veterinary Entomology and Arachnology.

The received digital material was subjected to statistical processing in Excel with the calculation of mean square deviations $(\mathrm{M} \pm \mathrm{m})$. The reliability of values was estimated according to the Stuart-Fischer probability table depending on the sample number. The probability of differences was estimated at $\mathrm{P}<0.05$.

\section{RESULTS AND DISCUSSION}

It was found that cattle demodicosis is widespread in Tyumen region and makes $43.5 \pm 1.03 \%$. The incidence rate of demodicosis in farms and complexes on the production of milk, beef and the rearing stock makes from 1.5 to $44.6 \%$. The smallest indicators of extensiveness and intensity of invasion were observed in bull-calves on feed $-4.9 \%$ and in the young stock up to 12 months old - $11.2 \%$, while the highest indicators were observed in heifers of $1.5-2$ years old $-56.7 \%$ and cows $-19.8 \%$. During the study the animals had the following prevalence levels: low $-73.6 \%$, average $-22.5 \%$, high $-3.1 \%$, generalized $-0.8 \%$.

The low prevalence of the young stock may be explained by slow development of invasion. The feeder bull calves that generally die before the first seasonal molt are also killed at early age. Besides, in farms they are subjected to early chemotherapy against hypodermosis and other ectoparasites with the use of systemically active acaricides, which, according to the study, are also destructive for Demodex bovis. The manure heifers after the first seasonal molt have increased demodectic invasion, and by the first calving the extensiveness and intensity of invasion reaches its maximum.

Seasonal dynamics of cattle demodicosis is very different. The intensity and extensiveness of invasion increases from January to July-August, and then decreases naturally repeating the same dynamics annually. The invasion increases since the beginning of a host molt and continues until the end of summer followed by the recession of demodectic invasion due to feed shortage of a parasite thus causing the need for migration to new hair follicles.

The typical clinical feature of cattle demodicosis is the presence of different skin papules. Demodectic colonies have two forms. Some of them are fine having the size of a millet grain, located in a skin surface layer, while the others are large having an oval form up to $20 \mathrm{~mm}$ in diameter, localized in a skin thickness. Fine colonies are located in the perineal area or on the inner surface of back extremities. With time, the papules do not get bigger and do not change their localization, i.e. they always locate close to skin surface. They were found on various cattle body parts, but most often on the back - from scapula to sacrum.

At the beginning of the pathology the papules of the second type are small and are similar in size to papules of the first type, but are located so deep under skin that they are difficult to find even through careful palpation. Later, such papules become bigger, and can be detected not only through palpation, but also through standard examination of the animal body surface.

In some cases, the difference in size of papules is explained by the colonization of Demodex bovis in hair follicles of transition hair thus resulting in skin rash, while in other cases - of guard hair thus forming large demodectic colonies of the second type lying deep under skin. After cutting the hair in places of demodectic papules, the following situation was observed. The visible diseased areas on surface skin layers had a scab, which removal revealed the channel leading inside the demodectic colony. Having removed a scab, 
it was possible to squeeze out from a papule a small amount of pasty content mainly consisting of mature Demodex bovis.

The nodules lying deep under skin resemble papules or pustules. Even at significant effort it is impossible to squeeze out the content from papules without preliminary puncture of its wall with a needle. On the contrary, when squeezing from pustule sides the scab closing an opening was separated and the content poured out. Demodex bovis were found there during the microscopy. The issue of differential diagnostics of cattle demodicosis against other diseases is solved quite quickly and easily via the microscopic study if it is possible to take out the pasty content with Demodex bovis from the demodectic center.

The study of cattle homeostasis of demodectic invasion included morphological and biochemical blood analyses. The analysis of a functional status of animals (Table 1) showed that the low demodectic invasion reduced the number of erythrocytes by $3.39 \%(5.4 \pm 0.47 \times 1012 / 1)$, average - by $8.23 \%(5.13 \pm 0.41 \times 1012 / 1)$ and high - by $19.5 \%(4.5 \pm 0.33$ $\mathrm{x} 1012 / 1)$ against $5.59 \pm 0.45 \times 1012 / 1$ of apparently healthy animals.

The corpuscular volume in case of demodicosis was slightly lower than in case of apparently healthy animals (44.9 $\pm 3.15 \mathrm{fl}$ ) by $2.23 \%$ at low degree, by $10.2 \%$ at average degree and by $16.7 \%$ at high degree of prevalence.
The erythrocyte sedimentation rate of test groups was increased in relation to the control one $(0.5 \pm 0.02 \mathrm{~mm} / \mathrm{h})$ by $22 \%(0.61 \pm 0.03 \mathrm{~mm} / \mathrm{h})$, by $38 \%(0.69 \pm 0.03 \mathrm{~mm} / \mathrm{h})$ and by $56 \%(0.78 \pm 0.045 \mathrm{~mm} / \mathrm{h})$ respectively.

The analysis of indicators regarding the number of erythrocytes, corpuscular volume, cellular hemoglobin content and concentration in erythrocytes makes it possible to conclude that their reduction demonstrates the decrease of oxygen supply to tissues and organs of a macroorganism in case of demodicosis, i.e. results in hypoxia.

The counting of blood corpuscles of animals having demodicosis showed that the number of leucocytes increased with the average prevalence by $19.7 \%(7.9 \pm 0.68 \times 109 / 1)$ and with high prevalence by $48.5 \%(9.8 \pm 0.73 \times 109 / 1)$ against $6.6 \pm 0.56 \times 109 / 1$ in the control group.

The leukogram analysis of cattle demodicosis showed that the level of stab neutrophils increases by $7.5 \%(2.15 \pm 0.22 \%)$, by $28 \% \quad(2.56 \pm 0.21 \%)$ and by $44.5 \% \quad(2.89 \pm 0.30 \%)$ respectively against the control group $(2.0 \pm 0.18 \%)$; the level of segmented neutrophils by $1.91 \%(21.3 \pm 1.55 \%)$, by $4.78 \%$ $(21.9 \pm 1.49 \%)$ and by $9.09 \% \quad(22.8 \pm 1.53 \%)$ respectively against $20.9 \pm 1.65 \%$ of the control group. The number of eosinophils increased at low prevalence by $24.1 \%$, at average prevalence - by $31.03 \%$ and at high prevalence - by $41.3 \%$ in relation to the control group.

TABLE I. HEMATOLOGICAL BLOOD INDICATORS OF CATTLE WITH DEMODICOSIS IN TYUMEN REGION (M \pm M)

\begin{tabular}{|c|c|c|c|c|c|}
\hline \multirow[b]{2}{*}{ Indicator } & \multirow[b]{2}{*}{$\mathbf{U M}$} & \multirow{2}{*}{$\begin{array}{c}\text { Healthy animals } \\
\text { Control } \\
(n=10)\end{array}$} & \multicolumn{3}{|c|}{ Diseased animals } \\
\hline & & & $\begin{array}{c}\text { Low } \\
(n=7)\end{array}$ & $\begin{array}{c}\text { Average } \\
(n=7)\end{array}$ & $\begin{array}{l}\text { High } \\
(n=7)\end{array}$ \\
\hline Erythrocytes & $10^{12 / 1}$ & $5.59 \pm 0.45$ & $5.4 \pm 0.47$ & $5.13 \pm 0.41 *$ & $4.5 \pm 0.33^{*}$ \\
\hline Corpuscular volume & fl & $44.9 \pm 3.15$ & $43.9 \pm 2.91$ & $40.3 \pm 2.85$ & $37.4 \pm 2.15^{*}$ \\
\hline Hemoglobin & $\mathrm{g} / 1$ & $121.3 \pm 5.13$ & $106.6 \pm 5.47 *$ & $101.8 \pm 3.45^{*}$ & $98.7 \pm 3.68 *$ \\
\hline Cellular hemoglobin content & pg & $32.5 \pm 1.01$ & $18.2 \pm 1.45^{*}$ & $16.6 \pm 0.64 *$ & $14.1 \pm 1.26^{*}$ \\
\hline $\begin{array}{c}\text { Cellular hemoglobin } \\
\text { concentration }\end{array}$ & $\mathrm{gl}$ & $393.5 \pm 4.78$ & $386.1 \pm 5.09 *$ & $376.5 \pm 4.39^{*}$ & $363.1 \pm 4.53^{*}$ \\
\hline Erythrocyte sedimentation rate & $\mathrm{mm} / \mathrm{h}$ & $0.5 \pm 0.02$ & $0.61 \pm 0.03 *$ & $0.69 \pm 0.03^{*}$ & $0.78 \pm 0.045^{*}$ \\
\hline Leukocytes & $10^{9} / 1$ & $6.6 \pm 0.56$ & $6.9 \pm 0.71$ & $7.9 \pm 0.68^{*}$ & $9.8 \pm 0.73 *$ \\
\hline Band neutrophils & $\%$ & $2.0 \pm 0.18$ & $2.15 \pm 0.22$ & $2.56 \pm 0.21^{*}$ & $2.89 \pm 0.30 *$ \\
\hline Segmented neutrophils & $\%$ & $20.9 \pm 1.65$ & $21.3 \pm 1.55$ & $21.9 \pm 1.49$ & $22.8 \pm 1.53$ \\
\hline Eosinophils & $\%$ & $2.9 \pm 0.20$ & $3.6 \pm 0.28 *$ & $3.8 \pm 0.27 *$ & $4.1 \pm 0.34 *$ \\
\hline Monocytes & $\%$ & $2.9 \pm 0.17$ & $1.8 \pm 0.11 *$ & $1.6 \pm 0.09 *$ & $1.56 \pm 0.12 *$ \\
\hline Lymphocytes & $\%$ & $60.3 \pm 2.31$ & $57.6 \pm 2.18$ & $55.5 \pm 2.10^{*}$ & $54.6 \pm 2.03 *$ \\
\hline Blood platelets & $10^{9} / 1$ & $296.0 \pm 6.15$ & $271.0 \pm 6.09^{*}$ & $258.4 \pm 5.38^{*}$ & $231.5 \pm 5.71 *$ \\
\hline Platelets volume & $\mathrm{fl}$ & $7.6 \pm 0.61$ & $7.1 \pm 0.63$ & $6.8 \pm 0.58$ & $6.1 \pm 0.46^{*}$ \\
\hline
\end{tabular}

a. Note: * statistical assurance of differences in relation to the control group at $\mathrm{P}<0.05$

The analysis of monocytes showed the reduction of their level in blood at low, average and high prevalence by $37.9 \%$, by $44.8 \%$ and by $46.2 \%$ respectively in comparison with healthy animals, the reduction of lymphocytes by $4.47 \%$, by $7.96 \%$ and by $9.45 \%$ respectively against the control group.

All animals affected by Demodex bovis demonstrate the reduction of the platelet count at low prevalence by $8.4 \%$ $(271.0 \pm 6.09 \times 109 / 1)$, at average prevalence - by $12.7 \%$ $(258.4 \pm 5.38 \times 109 / 1)$ and at high prevalence - by $21.8 \%$ $(231.5 \pm 5.71 \times 109 / 1)$ respectively against $296.0 \pm 6.15 \times 109 / 1$ in the control group, and the volume of thrombocytes by $6.5 \%$, by $10.5 \%$ and by $19.7 \%$ against $7.6 \pm 0.61 \mathrm{fl}$ in the control group.

Monocytopenia and hypolymphemia indicate the immunosupressive action of Demodex bovis on the organism of diseased animals and failure of immune T-system.

Thrombocytopenia in case of cattle demodicosis demonstrates the phagocytosis potential of thrombocytes (absorption of foreign elements) and their ability to participate in local inflammatory skin reactions.

The biochemical blood analysis showed that cattle with demodectic invasion is characterized by the increase in the 
total protein content at low prevalence by $1.9 \%(65.7 \pm 4.2 \mathrm{gl})$, at average prevalence by $11.3 \%(71.8 \pm 5.03 \mathrm{gl})$ and at high prevalence by $33.8 \%(86.3 \pm 4.89 \mathrm{gl})$ against $64.5 \pm 1.73 \mathrm{gl}$ of apparently healthy animals, the increase in albumins by $8.1 \%$ $(42.8 \pm 1.75 \%), \quad 14.4 \% \quad(45.3 \pm 1.98 \%)$ and by $20.9 \%$ $(47.9 \pm 1.85 \%)$ against $39.6 \pm 1.75 \%$ and the reduction of globulins by $5.3 \%(57.2 \pm 1.081 \%), 9.4 \%(54.7 \pm 1.32 \%)$ and by $13.7 \%(52.1 \pm 1.43 \%)$ against $60.4 \pm 1.75 \%$ (Table 2). Most likely, the increase of the albumin-rich fraction is caused by the response of cattle organism to parasitizing with Demodex bovis, while the decrease of the globulin-rich fraction - by its immunodeficiency.

The ratio of albumins/globulins at low, average and high prevalence naturally increased by $13.8 \%, 27.7 \%$ and $40.0 \%$ respectively against $0.65 \pm 0.047$ in the control group, which is typical for any inflammatory process.

To define the functional performance of a liver in case of cattle demodicosis, such indicators as aspartate transaminase (AST), alanine aminotransferase (ALT), alkaline phosphatase, bilirubin, cholesterol, thymol test were studied.

The functional indicators of liver were generally increased: aspartate transaminase (AST) at low prevalence by $11.8 \%$, at average by $21.9 \%$ and at high by $36.3 \%$ in comparison with healthy animals, alanine aminotransferase (ALT) - by $28.3 \%$, 2 times and 2.3 times respectively, alkaline phosphatase by $39.4 \%, 61.7 \%$ and $77.5 \%$, bilirubin by $13.8 \%, 46.1 \%$ and $65.7 \%$, cholesterol by $5.2 \%, 7.8 \%$ and $10.6 \%$ and thymol by $60 \%, 2$ times and 2.7 times

TABLE II. BIOCHEMICAL BLOOD INDICATORS OF CATTLE WITH DEMODICOSIS IN TYUMEN REGION (M \pm M)

\begin{tabular}{|c|c|c|c|c|c|}
\hline \multirow[t]{2}{*}{ Indicator } & \multirow[t]{2}{*}{ MU } & \multirow{2}{*}{$\begin{array}{c}\text { Healthy animals } \\
\begin{array}{c}\text { Control } \\
(n=10)\end{array}\end{array}$} & \multicolumn{3}{|c|}{ Diseased animals } \\
\hline & & & $\begin{array}{c}\text { Low } \\
(n=7)\end{array}$ & $\begin{array}{c}\text { Average } \\
(n=7)\end{array}$ & $\begin{array}{l}\text { High } \\
(n=7)\end{array}$ \\
\hline Total protein & gl & $64.5 \pm 1.73$ & $65.7 \pm 4.2^{*}$ & $71.8 \pm 5.03 *$ & $86.3 \pm 4.89 *$ \\
\hline Albumins & $\%$ & $39.6 \pm 1.75$ & $42.8 \pm 2.75^{*}$ & $45.3 \pm 1.98 *$ & $47.9 \pm 1.85^{*}$ \\
\hline Globulins: & $\%$ & $60.4 \pm 1.75$ & $57.2 \pm 1.08^{*}$ & $54.7 \pm 1.32 *$ & $52.1 \pm 1.43 *$ \\
\hline$\alpha$ & $\%$ & $15.14 \pm 1.571$ & $10.3 \pm 0.95 *$ & $10.0 \pm 0.56^{*}$ & $9.4 \pm 0.504 *$ \\
\hline$\beta$ & $\%$ & $10.16 \pm 1.981$ & $9.6 \pm 0.84$ & $8.6 \pm 0.78$ & $8.4 \pm 0.96^{*}$ \\
\hline$\gamma$ & $\%$ & $35.4 \pm 1.95$ & $32.3 \pm 2.45$ & $31.1 \pm 2.64 *$ & $28.3 \pm 2.57 *$ \\
\hline Albumin/globulin ratio & $\%$ & $0.65 \pm 0.047$ & $0.74 \pm 0.009 *$ & $0.83 \pm 0.025^{*}$ & $0.91 \pm 0.039^{*}$ \\
\hline Glucose & $\mathrm{mmol} / \mathrm{l}$ & $3.4 \pm 0.21$ & $3.47 \pm 0.876$ & $3.52 \pm 0.489 *$ & $3.70 \pm 0.568^{*}$ \\
\hline Total bilirubin & micromole/l & $4.12 \pm 0.153$ & $4.69 \pm 0.985^{*}$ & $6.02 \pm 1.623^{*}$ & $6.83 \pm 1.235^{*}$ \\
\hline Rest nitrogen & $\mathrm{mmol} / \mathrm{l}$ & $16.3 \pm 1.203$ & $18.7 \pm 1.98$ & $24.3 \pm 2.56^{*}$ & $29.9 \pm 1.86^{*}$ \\
\hline BUN & $\mathrm{mmol} / \mathrm{l}$ & $5.4 \pm 0.38$ & $5.84 \pm 1.002$ & $6.15 \pm 0.935^{*}$ & $8.64 \pm 0.964 *$ \\
\hline AST & $\mathrm{u} / 1$ & $34.12 \pm 1.685$ & $38.16 \pm 3.568$ & $41.6 \pm 2.64 *$ & $46.5 \pm 3.009^{*}$ \\
\hline ALT & $\mathrm{u} / 1$ & $14.5 \pm 1.87$ & $18.6 \pm 3.41 *$ & $29.15 \pm 1.245^{*}$ & $33.7 \pm 1.56^{*}$ \\
\hline Thymol test & pes & $0.58 \pm 0.136$ & $0.93 \pm 0.654$ & $1.18 \pm 0.463^{*}$ & $1.58 \pm 0.323^{*}$ \\
\hline Cholesterol & $\mathrm{mmol} / \mathrm{l}$ & $6.15 \pm 0.139$ & $6.47 \pm 0.934$ & $6.63 \pm 0.928 *$ & $6.80 \pm 0.941 *$ \\
\hline Creatinine & micromole/1 & $38.5 \pm 1.09$ & $78.69 \pm 4.37 *$ & $86.67 \pm 3.89^{*}$ & $93.73 \pm 5.214^{*}$ \\
\hline Alpha amylase & $\mathrm{u} / 1$ & $85.3 \pm 3.16$ & $93.8 \pm 2.59 *$ & $99.7 \pm 2.13^{*}$ & $109.4 \pm 3.09 *$ \\
\hline Serum iron & micromole/1 & $25.75 \pm 1.845$ & $20.75 \pm 2.68$ & $17.65 \pm 1.22^{*}$ & $15.65 \pm 1.713^{*}$ \\
\hline Calcium & $\mathrm{mmol} / 1$ & $2.56 \pm 0.153$ & $2.44 \pm 0.72$ & $2.38 \pm 0.37$ & $2.26 \pm 0.30$ \\
\hline Phosphorus & $\mathrm{mmol} / 1$ & $1.39 \pm 0.030$ & $1.42 \pm 0.30$ & $1.65 \pm 0.216^{*}$ & $1.87 \pm 0.108^{*}$ \\
\hline
\end{tabular}

The analysis of mineral metabolism indicators showed that the calcium content in the blood serum of animals with demodicosis of the 1 st, 2 nd and 3rd group was lower by $4.7 \%$, $7.03 \%$ and $11.7 \%$ in comparison with the control group, and the phosphorus content was higher by $2.2 \%, 18.7 \%$ and $34.5 \%$ respectively. The serum iron content of the control group was higher than that of cattle with low, average and high prevalence by $19.4 \%, 31.5 \%$ and $39.2 \%$ respectively, which indicates the decrease of respiratory exchange in tissues and organs of animals.

All animals affected by Demodex bovis showed the increase of creatinine, while in the group with high prevalence this increase was 2.4 times higher. The amylase activity increased in the first group by $9.7 \%$, in the second - by $16.9 \%$ and in the third - by $28.3 \%$ against the control group $85.3 \pm 3.16 \mathrm{u} / 1$, glucose - by $2.1 \%, 3.5 \%$ and $8.8 \%$ respectively against the control group $3.4 \pm 0.21 \mathrm{mmol} / \mathrm{l}$. The BUN concentration exceeded the control indicators of cattle with demodectic invasion by $8.1 \%, 13.8 \%$ and $60.0 \%$, filtrate nitrogen - by $14.7 \%, 49.0 \%$ and $83.4 \%$ respectively.

\section{CONCLUSIONS}

1. Cattle demodicosis is widespread in Tyumen region (prevalence: $43.5 \pm 1.03 \%$ ). The incidence rate of demodicosis in farms and complexes on the production of milk, beef and the rearing stock makes from 1.5 to $44.6 \%$. The smallest indicators of extensiveness and intensity of invasion were observed in bull-calves on feed $-4.9 \%$ and in the young stock up to 12 months old $-11.2 \%$, while the highest indicators were observed in heifers of 1.5-2 years old $-56.7 \%$ and cows $-19.8 \%$. During the study the animals had the following prevalence levels: low $-73.6 \%$, average $22.5 \%$, high $-3.1 \%$, generalized $-0.8 \%$.

2. The analysis of demodicosis showed the reduction of the number of erythrocytes, corpuscular volume, cellular 
hemoglobin content and concentration in erythrocytes, which demonstrates the decrease of oxygen supply to tissues and organs of animal organism. The reduction of monocytes and lymphocytes indicates the immunosupressive action of Demodex bovis on the host organism and failure of immune T-system.

3. The parasitizing with Demodex bovis damages liver, kidneys and metabolism of cattle organism in general.

\section{References}

[1] L.A. Glazunova, Yu.V. Glazunov, A.A. Ergashev, "Ecologicalepizootical situation on telasiosis among large cattle in northern Ural region", Research Journal of Pharmaceutical, Biological and Chemical Sciences, 2018, vol. 9, No. 4, pp. 1687-1693.

[2] N.A. Gavrilova, "Trombidiformes mites and diseases they cause", VetPharma, 2013, vol. 12, No. 1, pp. 82-85.

[3] S.V Larionov., F.I. Vasilevich, "Animal demodicosis", Moscow:IMAPRESS, 2001, p. 251

[4] Sivkov G.S., et al, "Protection of cattle against pathogens: Methodical recommendations", Tyumen, 2010, p. 152

[5] G.S. Sivkov, V.N. Domatsky, A.K. Metelitsa, Yu.V. Glazunov, O.A. Korotayeva, E.N. Maslova, F.I. Vasilevich, A.A Vodianov, S.V. Larionov, "Therapy and prevention of animal acariasis in the Russian Federation", Methodical recommendations, Tyumen, 2010, p. 56.

[6] L.N. Skosyrsky, "Assessment of demodicosis damages to semi-finished leather and finished goods", Scientific Journal of Pavlodar State University named after S. Toraygyrov, No. 2, 2004, pp. 103-105.
[7] L.N. Skosyrsky, "Characteristic of demodicosis skin injuries during processing", Herald of Krasnoyarsk State Agricultural University: Scientific and Technical Journal, No. 6, Krasnoyarsk, 2004, pp. 147149

[8] L.N. Skosyrsky, O.A. Stolbova, "Distribution and seasonal dynamics of cattle demodicosis in Tyumen region", Bulletin of Novosibirsk State Agricultural University, 2011, vol. 20, No. 4, pp. 94-96.

[9] O.A. Stolbova, L.A Glazunova., A.A. Nikonov, Yu.V. Glazunov, L.N. Skosyrsky, "Insects and mites - cattle parasites in the Northern TransUral region", Fundamental research, 2014, No. 11-12, pp. 2650-2655.

[10] O.A Stolbova, L.N. Skosyrsky, “Acaricidal activity of 'abifipr' medicine at cattle demodicosis", Herald of Krasnoyarsk State Agricultura University, 2016, No. 1, pp. 145-149.

[11] O.A. Stolbova, L.N. Skosyrsky, "Study of stress resistance at cattle demodicosis in Tyumen region", Questions of standard and legal regulation in veterinary science, 2015 , No. 2, pp. 84-86.

[12] O.A. Stolbova, L.N. Skosyrsky, "Calculation of acaricide costs in fight against cattle demodicosis", Bulletin of agrarian and industrial complex of Stavropol Territory, 2016, vol. 22, No. 2, pp. 54-57.

[13] O.A Stolbova., Yu.V. Glazunov, L.N. Skosyrskikh, "Mites-parasites of dogs in Northern Trans-Urals", Indo American Journal of Pharmaceutical Sciences, 2018, vol. 5, No. 3, pp. 1675-1682.

[14] O.A. Stolbova, "Acaricide activity of 'abifipr' medicine at dog demodicosis", Indo American Journal of Pharmaceutical Sciences, 2018, vol. 5 , No. 7, pp. 6594-6597.

[15] M.A. Chasovshchikova, O.M. Sheveleva, M.A. Svjazhenina, N.I Tatarkina, A.B. Satkeeva, A.A. Bakharev, E.A. Ponomareva, A.G Koshchaev, "Relationship between genetic variants of kappa-casein and prolactin and productive-biological characteristics of black-motley cows", Journal of Pharmaceutical Sciences and Research, 2017, vol. 9, No. 7, pp. 1038-1044. 